\title{
Interactive Games: Intrinsic and Extrinsic Motivation, Achievement, and Satisfaction
}

\author{
Bomi Kang ${ }^{1} \&$ Sophia H. Tan ${ }^{2}$ \\ ${ }^{1}$ Department of Marketing and Hospitality, Resort, and Tourism Management, E. Craig Wall Sr. College of Business \\ Administration, Coastal Carolina University, Conway, USA \\ ${ }^{2}$ Instructional Media Service Faculty, Center for Teaching, Learning and Technology, Phoenix College, Phoenix, \\ USA \\ Correspondence: Bomi Kang, Associate Professor, Department of Marketing and Hospitality, Resort, and Tourism \\ Management, E. Craig Wall Sr. College of Business Administration, Coastal Carolina University, Conway, SC \\ 29528-6054, USA. E-mail: bkang@coastal.edu
}

Received: October 22, 2014

Accepted: November 4, 2014

Online Published: November 12, 2014

doi:10.5430/jms.v5n4p110

URL: http://dx.doi.org/10.5430/jms.v5n4p110

\begin{abstract}
People who have played games have often experienced the process of being fully absorbed by the task, or Flow. Engaged students experience aroused pleasure that is synonymous with intrinsic motivation. This study $(\mathrm{N}=160)$ looks at whether the game-derived motivation continues to impact students' interest toward the subject matter at the end of the course, and whether it impacts their extrinsic motivation. In several college level courses where learning technology is the focus in class, we found a significant difference between the students' intrinsic motivation and achievement scores when they have had game-based activities in class as compared to traditional non-game-based learning activities. Authors discuss the corresponding implications, as well as the implications for our results showing no significant difference in the participants' extrinsic motivation and course satisfaction.
\end{abstract}

Keywords: interactive games, intrinsic motivation, extrinsic motivation, flow

\section{Introduction}

\subsection{Problem Statement}

Literature suggests that using games in learning can significantly increase learners' level of engagement, interest, competitiveness, achievement, motivation, teamwork, and learning (Evans, Pruett, Chang, \& Nino, 2013-2014; Lim, Nonis, \& Hedberg, 2006; Herrington, Oliver, \& Reeves, 2003; Prensky \& Thiarajan, 2007; Ketelhut, Dede, Clarke, \& Nelson, 2006; Azriel, Erthal, \& Starr, 2005).

Often, the student is emotionally charged, thereby increasing retention and learning, even if only indirectly for students who are not conscious of that learning process can be difficult (Brehm \& Self, 1989). According to Prensky and Thiarajan (2007), games not only support different learning styles, but also provide instructional coaching that help reinforce learning.

Researchers for decades synthesized why and how individuals are motivated in schools, work, sports, and other settings. The desire to experience competence and avoid experiencing incompetence, as well as for pleasure arousal, are inherent in human nature. People sometimes select to engage in certain activities for their inherent enjoyment and satisfaction of human needs for competence. Several researchers found that these pleasures and the feeling of fulfilment increases participants' intrinsic motivation (Cameron, Pierce, Banko, \& Gear, 2005; Charoenying, 2010; Wang, Lockee, \& Burton, 2011-2012).

Games provide the platform for people to experience pleasure, and feelings of competence, which lead to increased intrinsic motivation toward the gaming activity. To date, however, we are still not clear whether using interactive games in the classroom can lead to increased intrinsic motivation toward the subject matter, as well as increased course satisfaction. In other words, would students find the subject matter more "inherently" interesting and enjoyable as a result of playing interactive games in the class? Finally, would they perform better in class? In this paper, we seek to clarify this relationship between games and the type of motivation that it develops, and ultimately achievement and satisfaction. 


\subsection{Theoretical Perspectives}

Csikszentmihalyi (1990) used the concept of "flow" to refer to mental processes that are fully absorbed in a task, characterized by personal experiences of concentration, energy and success. This framework has been used by some researchers (Konradt \& Sulz, 2002; Lim, Nonis, \& Hedberg, 2006) to explain the intrinsic motivation felt by students when they are immersed in the game-based learning environment. Based on this concept, we believe that interactive game-based learning can increase intrinsic motivation. However, whether "flow" transfers intrinsic motivation from the task to the subject matter has yet been systematically studied.

Csikszentmihalyi (1990) also believed that the point system used for rewarding players in these game-based environments is a form of feedback that enhances flow. Games often use a system of extrinsic achievement-based rewards, such as praise, promotion, recognition, or points, to motivate participants. The most commonly used in-class games convert popular TV games into interactive games, such as Jeopardy, Who wants to be a Millionaire, Wheel of Fortune, and Hollywood Squares. These games feature money, praise, and promotion as part of the play. Even in more complex simulation games, there is a system of external reward system that recognizes the success of the player. As a point of clarification, these "external rewards" are not tangible or intangible rewards given by teacher to students, such as candy, or extra credits; these rewards refer to the point system and praises that are inherently a part of the games. When participants demonstrate their subject matter learning and knowledge, they accumulate these points. As such, they are considered achievement-based rewards. Some studies have found that the use of external rewards actually decreased motivation for a task for which the student initially was motivated. Meta-analytic studies have concluded that rewards can lead to increased intrinsic motivation, if they are informational, and tied to their achievement or standards or goals (Deci, Ryan, \&Keostner, 1999).

In a line of research on achievement-based rewards, Cameron, Pierce, Banko, and Gear (2005) found that achievement-based rewards during learning or testing can increase participants' intrinsic motivation. Although Cameron et al. (2005) did not use game-based learning in their research studies, we believe that the concept can be applied to interactive games, since the games offer participants rewards for success. In fact, some researchers think that intrinsic motivation increases as rewards are tied to increasingly demanding tasks (Pierce, Cameron, Banko, \& So, 2003) - a very similar scenario in gaming where tasks often become increasingly demanding as players progress through stages.

As early as 1987, Marlone and Lepper have researched on fostering intrinsic motivation through learning environments to inform us on how digital games could affect intrinsic motivation. Marlone and Lepper (1987) used the addictive nature of computer games as a platform to suggest that intrinsic motivation can be fostered through learning environments that encourage challenge, curiosity, fantasy, and control. Their taxonomy leads us to believe that the use of digital games could promote these factors, thus increase intrinsic motivation. However, Marlone and Lepper's studies suggest that people are intrinsically motivated to play computer games, but did not specify whether the use of game-based learning was able to sustain intrinsic motivation toward the subject matter.

In more recent studies, literature has consistently showed a positive correlation between playing games in class and students' achievement (Huizenga, Admiraal, Akkerman, \& Dam, 2009; Tuzun, Yilmaz-Soylu, Karakus, Inal, \& Kizilkaya, 2009), but has not shown consistency in predicting games' impact on students' intrinsic and extrinsic motivation to learn. In one study, Huizenga, Admiraal, Akkerman, and Dam (2009) found that students who used mobile games in classes performed significantly better than those who engaged in project-based instruction, though their motivation for the subject matter was not significantly different. In another study on game-based activities on primary school students' achievement and motivation (Miller, Shell, Khandaker, \& Soh, 2010-2011;Tuzun, Yilmaz-Soylu, Karakus, Inal, \& Kizilkaya 2009), it was found that game-based environment increased students' achievement, and intrinsic motivation, and interestingly, decreased students' extrinsic motivation to learn geography. Particularly, the students had decreased their focus on getting grades.

In this study, we are curious as to whether playing interactive games during the learning process can lead to students becoming inherently interested in the subject matter, or whether students remain extrinsically motivated. We contend that since game-based learning utilizes achievement-based rewards and increases flow, it will ultimately lead to increased intrinsic motivation, as well as achievement, and course satisfaction.

\subsection{Research Questions and Their Correspondence to Research Design}

While the effects of educational games in classes are well studied, there is little attempt made in researching game-based learning, especially in the higher education (Ebner \& Holzinger, 2007). This study takes some of the most popular and easily available games on the internet, such as Jeopardy, and proposes that the use of these games in class would increase students' motivation to learn, their course satisfaction, and learning achievement in 
comparison with non-game based tasks. These games are chosen for a number of reasons. Not only do they have widespread popularity, but they can also be easily brought into the classroom due to the accessibility of the internet and other application software. It is conceivable for most classrooms to be able to access these materials on the internet, and to align them with specific lesson objectives. In addition, they have clearly structured achievement-based rewards built into the games in terms of the points and praises that participants can accumulate through demonstrating that they have learned the subject matter.

The research is conducted in four different undergraduate level classes. Traditionally, students from these classes have used lecture, group projects, class discussions, and individual assignments as learning activities. With the consistent use of more well-designed, interactive games which are aligned with course objectives, we believe that it would increase students' motivation to learn, their course satisfaction, and achievement in comparison with more traditional class assignments. Therefore, we propose the following research questions:

1) What are the effects of interactive game-based learning on students' intrinsic and extrinsic motivation to learn?

2) What are the effects of interactive game-based learning on students' achievement?

3) What are the effects of interactive game-based learning on students' overall satisfaction with the course?

\section{Method}

\subsection{Research Design}

This study utilizes a quasi-experimental design involving four undergraduate classes, two of which are treatment groups, and the other two are control groups. The control group received traditional forms of in-class assignments such as worksheets or class discussions. The treatment groups received various interactive games specifically designed for student learning aligned with course objectives. The participants received four interactive game activities during the second half of the semester. These treatments were given in computer labs after each chapter was covered by the instructors.

\subsection{Participant (Subject) Characteristics}

The participants of this study were chosen from four undergraduate classes in two subject areas: Management Information Systems from Business College (65 students) and Computer Technology/Instructional Media from educational college (40 students), at the mid-sized state university in southeast United States. These two courses cover somewhat similar contents in that both classes cover topics related to application of computer and information technology. However, the emphases were placed on different fields; business in the MIS classes whereas teaching for instructional technology classes.

\subsection{Measures and Covariates}

At the beginning of the semester, participants were asked to rate their expectation of the course on several aspects (measure by 7-point Likert scale) and rate their motivation level to learn the subject. Academic Motivation Scale (AMS) was adopted (Vallerand, Pelletier, Blais, Briere, Senecal, \& Vallieres, 1992) and modified to measure students' motivational state. The AMS (Vallerand et al., 1992) is a 28 -item scale designed to assess autonomous and extrinsic regulatory styles. It intends to measure seven underlying constructs of motivation: three types of intrinsic motivation (to experience stimulation, to know, and to accomplish), three types of extrinsic motivation (identified regulation, introjected regulation, external regulation), and amotivation. Extra question regarding overall motivation was added and rated on the same 7-point Likert scale.

Satisfaction was measured at the end of the semester. The survey used multi-items adapted from Kleen \& Shell (2001). Participants responded to each statement on a 7-point Likert scale.

\subsection{Experimental Manipulations or Interventions}

The pre-test and post-test are composed of 30 true and false, and multiple choices questions. Half of the questions (15) were identical for all 4 sections, and the other half was course content-specific. We conducted a t-test on pre-test scores to check differences in students' basic computer-related knowledge competency. The test shows that there was significant difference in two groups ( $(103)=2.45, \mathrm{p}=.02)$ : the mean pre-test score of business classes was 18.25 $(\mathrm{SD}=.57)$ whereas that of education classes was $16.20(\mathrm{SD}=.51)$. This was an expected result because business class is upper level class with computer related pre-requisite while the education class is lower level class without any pre-requisite.

The motivation survey was conducted twice for each class, before and after the treatment of interactive games. At the end of the semester, we collected data on student satisfaction, and achievement score. These are compared across groups to see the treatment effect (interactive games). 


\section{Results}

\subsection{Statistics and Data Analysis}

From the original data set of 199, thirty nine (39) influential points were removed, resulting in 160 valid data. Missing data were replaced with series means.

The results of factor-analysis (Principle Component Analysis with varimax rotation) on AMS suggested a 3 factor model. Eigenvalue over 1 was used for cutoff points for the decision. This model explained $70 \%$ of total variance of motivation. KMO measure of adequacy was .89 showing the data were appropriate for factor analysis. Eleven (11) ambiguous and cross loaded items were removed, and17 items were retained for final model. Those 17 items are presented in Appendix1. All three motivational factors showed acceptable reliability, with Cronbach's alpha value of 0.89 or above. Factor scores were retained using regression method. Retained factor scores were used for further t-tests, to determine the impact of interactive games. Result of EFA is presented in Table 1.

Table 1. EFA results

\begin{tabular}{llll}
\hline Item & Extrinsic & Intrinsic & Amotivation \\
\hline EX1 & .852 & & \\
EX2 & .817 & & \\
EX3 & .803 & & \\
EX4 & .770 & & \\
EX5 & .740 & & \\
EX6 & .772 & & \\
\hline IN1 & & .793 & \\
IN2 & & .792 & \\
IN3 & & .745 & \\
IN4 & & .725 & \\
IN5 & & .704 & \\
IN6 & & .669 & \\
IN7 & & .535 & \\
\hline AM1 & & & .905 \\
AM2 & & & .902 \\
AM3 & & & .879 \\
AM4 & & & .860 \\
\hline Eigenvalues & 7.047 & 3.495 & 1.352 \\
\hline \% of variance explained & 26.177 & 23.849 & 19.946 \\
\hline Cronbach's Alpha & .916 & .887 & .919 \\
\hline
\end{tabular}

Note: EX refers to extrinsic motivation, IN refers to intrinsic motivation, and AM refers to amotivation.

\subsection{Hypotheses Tests}

Next, a series of paired t-test was conducted to examine if playing interactive games would affect students' intrinsic, extrinsic, and overall motivation to learn about the subject. Secondly, another paired t-test was conducted on pre and post test scores in order to examine the impact of interactive games on students' achievement. Finally, students' satisfaction with the course was accessed using t-test. See Table 2 for the results of paired t-tests.

Table 2. T-test results

\begin{tabular}{lcccc}
\hline & $\mathrm{t}$-value & $\mathrm{N}$ & $\begin{array}{c}\text { Mean score after } \\
\text { playing games }\end{array}$ & $\begin{array}{c}\text { Mean score before } \\
\text { playing games }\end{array}$ \\
Intrinsic motivation & $3.28^{* *}$ & 77 & .349 & -.2998 \\
Extrinsic motivation & 1.04 & 77 & .078 & -.0668 \\
Overall motivation & $2.15^{*}$ & 78 & 5.79 & 5.42 \\
Post-Pre test scores & $3.20^{* *}$ & 72 & 22.94 & 17.31 \\
Satisfaction & 3.18 & 78 & 5.77 & 5.70 \\
& $(0.73)$ & & & \\
& & & &
\end{tabular}


The results show that interactive games significantly increased students' intrinsic motivation, $t=3.281, p<.01$ as well as overall motivation, $\mathrm{t}=2.15, \mathrm{p}<.05$. Interestingly, however, the increase in the amount of extrinsic motivation was not statistically significant for treatment and control groups.

In addition, a paired t-test on students' post and pre test scores showed that playing interactive games has a significant impact on student achievement score, $\mathrm{t}=3.20, \mathrm{p}<.01$. However, there was only a marginal increase in students' overall satisfaction due to playing interactive games, $\mathrm{t}=1.81, \mathrm{p}=0.73$. The difference was not statistically significant.

\section{Discussion}

Our findings corroborate previous studies that also showed the impact of game-based learning on students' intrinsic motivation toward the subject matter. The games inherently have a system that rewards achievement, leading to Flow, a state in which learners are fully absorbed by the goals of the activity - to learn the subject matter. In this state, the learners are engaged in the subject matter because they find intrinsic pleasure in doing so. The fact that the participants' intrinsic motivation toward subject matter is significantly higher) after game-based learning activities suggests that there is a very direct and close tie between participants' flow during the game and their motivation toward the subject matter. In other words, the flow that they experience during the interactive games is not limited to the game environment, but is extended or transferred onto the subject matter.

Our results are contrary to some studies. For example, Tuzun et al. (2009) suggested that mobile games do not increase motivation. Perhaps the difference between digital computer-based games, and interactive game-based classroom activities is much more significant than the literature suggests. This is reasonable, given that the two environments are drastically different. The interactive games used in our study are different from other computer-based games because the game or the "action" happens in the actual classroom as opposed to the "action" happening on the computer in most digital games. This difference might have caused one to be more closely associated with the subject matter than the other. Another reason may be the interactive and collaborative nature of our games versus the ones used in other studies. Future studies will have to research this more closely to be more definitive in explaining the difference.

Consistent with most other literature, our study shows that there is a significant increase in students' test scores when treated with game-based learning activities. There seems to be a direct link between the increase in intrinsic motivation and the increase in students' achievement. As suggested by the flow theory, students can become so engaged and involved in the activities that they can forget about time; and they can take so much pleasure in learning the subject that they could learn more than they otherwise would have.

What was interesting was the extrinsic motivation remained about the same. Even though much of the motivation driven by the games could be arguably more extrinsic in nature, changes in participants' extrinsic motivation remained statistically insignificant despite the treatment. This substantiates literature on achievement based rewards, which have been theorized to increase students' intrinsic motivation. The achievement based rewards that the participants experienced while playing those games have likely increased their pleasure toward the subject matter, but have made no difference in their extrinsic motivation toward the subject matter. It is highly probable that the students' increased pleasure toward the subject matter does not change the likelihood that the subject matter may offer them extrinsic rewards, such as finding a better job in the future or graduating from college. This suggests that intrinsic motivation is not the opposite of extrinsic motivation, but rather, they operate on separate continuums.

Although the participants of games were more intrinsically motivated toward the subject matter, their course satisfaction with the course was not statistically different than the non-game-based counterpart. The mean increased from 5.70 to 5.77, but this increase was not statistically significant at the 0.05 level. This suggests that increase in overall motivation may not be correlated with higher course satisfaction scores. In fact, one might argue that students who are more motivated take more interest in the subject matter and are likely to be more critical during course evaluations, or pay more attention to instructor's organizational skills or personality, as opposed to those who are less interested in the subject matter. Again, this is another area for future research.

Literature has established that games can be a very powerful tool in increasing student engagement and motivation. This study has attempted to fill in some gaps by finding out the type of motivation that game-based learning fosters, and whether the motivational results can be generalized or transferred to the learning of the subject matter, and whether that ultimately result higher achievement scores and course satisfaction. Currently, there is limited research in this area, especially in the higher-education classrooms (Ebner \& Holzinger, 2007).

The empirical evidence from this study provides some insight this topic by suggesting that intrinsic motivation 
derived from digital games does generalize to the learning of the subject matter. In addition, our results support the literature that has expounded on the benefits of interactive game-based learning. Further, our results validate the use of practical and easily obtainable interactive games for learning, by showing that they could result in significantly higher achievement scores. These results are likely to be highly relevant to other researchers and educators.

\section{References}

Azriel, J A., Erthal, M. J., \& Starr, E. (2005). Answers, Questions, and Deceptions: What Is The Role of Games in Business Education? Journal of Education for Business, 81(1), 9-14. http://dx.doi.org/10.3200/JOEB.81.1.9-14

Brehm, J. W., \& Self, E. A. (1989). The Intensity of Motivation. Annual Review of Psychology, 40, 109-131. http://dx.doi.org/10.1146/annurev.ps.40.020189.000545

Cameron, J., Pierce, W. D., Banko, K. M., \& Gear, A. (2005). Achievement-based rewards and intrinsic motivation: a test of cognitive mediators. Journal of Educational Psychology, 97(4), 641-655. http://dx.doi.org/10.1037/0022-0663.97.4.641

Charoenying, T. (2010). Accountable game design: Structuring the dynamics of student learning interactions. Journal of Educational Computing Research, 43(2), 135-163. http://dx.doi.org/10.2190/EC.43.2.a

Csikszentmihalyi, M. (1990). Flow: The Psychology of Optimal Experience. New York: Harper and Row.

Ebner, M., \& Holzinger, A. (2007). Successful implementation of user-centered game-based learning in higher education: An example from civil engineering. Computers and Education, 49(3), 873-890. http://dx.doi.org/10.1016/j.compedu.2005.11.026

Evans, M. A., Pruett, J., Chang, M., \& Nino, M. (2013-2014). Designing personalized learning products for middle school mathematics: The case for networked learning games. Journal of Educational Technology, 42(3), 235-254.

Herrington, J., Oliver, R., \& Reeves, T.C. (2003). Patterns of engagement in authentic online learning environments. $\begin{array}{lllll}\text { Australian } & \text { Journal }\end{array}$ http://dx.doi.org/10.1111/j.1467-8535.2006.00531.x

Huizenga, J., Admiraal, W., Akkerman, S., \& Dam, G. ten (2009) Engagement, Motivation and Learning in a Mobile City Game. Journal of Computer Assisted Learning, 25(4), 332-344. http://dx.doi.org/10.1111/j.1365-2729.2009.00316.x

Ketelhut, D. J., Dede, C., Clarke, J., \& Nelson, B. (2006). A multi-user virtual environment for building higher order inquiry skills in science. Paper presented at the American Educational Research Association, San Francisco, CA.

Kleen, B., \& Shell, W. L. (2001). Servqual-based measurement of student satisfaction with classroom instructional technologies: A 2001 update. Proceedings of the 16th Annual Conference of the International Academy for Information Management, New Orleans, LA., 226-235.

Konradt, U., \& Sulz, K. (2001). The experience of flow in interacting with a hypermedia learning environment. Journal of Educational Multimedia and Hypermedia, 10(1), 69-84.

Lim, C. P., Nonis, D., \& Hedberg, J. (2006). Gaming in a 3D multiuser virtual environment: engaging students in Science lessons. British Journal of Educational Technology, 37(2), 211-231.

Marlone, T. W., \& Lepper, M. R. (1987). Making Learning Fun: A Taxonomy of Intrinsic Motivations for Learning, in Aptitude, Learning and Instruction: III. In Snow, R.E. and Farr, M.J. (Eds.), Conative and affective process analyses (pp. 223-253). Erlbaum: Hilsdale, NJ.

Miller, L. D., Shell, D., Khandaker, N., \& Soh, L. (2010-2011). Teaching using computer games. Journal of Educational Technology Systems, 39(3), 321-343. http://dx.doi.org/10.2190/ET.39.3.g

Pierce, W. D., Cameron, J., Banko, K. M., \& So, S. (2003). Positive Effects of rewards and performance standards on intrinsic motivation. Psychological Record, 53, 561-579.

Prensky, M., \& Thiagarajan, S. (2007). Digital Game-Based Learning. St. Paul, MN: Paragon House.

Ryan, R. M., \& Deci, E. L. (2000). Self-determination theory and the facilitation of intrinsic motivation, social development, and well-being. American Psychologist, 55, 68-78. http://dx.doi.org/10.1037/0003-066X.55.1.68 
Tuzun, H., Yilmaz-Soylu, M., Karakus, T. Inal, Y., \& Kizilkaya, G. (2009). The effects of computer games on primary school students' achievement and motivation in geography learning. Computers \& Education, 52(1), 68-77. http://dx.doi.org/10.1016/j.compedu.2008.06.008

Vallerand, R. J., Pelletier, L.G., Blais, M. R., Briere, N. M., Senecal, C., \& Vallieres, E. F. (1992). The academic motivation scale: A measure of intrinsic, extrinsic, and amotivation in education. Educational and Psychological Measurement, 52, 1003-1017. http://dx.doi.org/10.1177/0013164492052004025

Wang, F., Lockee, B. B., \& Burton, J. K. (2011-2012). Computer game-based learning: Perceptions and experiences of senior Chinese Adults. Journal of Educational Technology System, 40(1), 45-58. http://dx.doi.org/10.2190/ET.40.1.e

\section{Appendix}

Extrinsic Motivation

EX1 Because eventually it will enable me to enter the job market in a field that I like.

EX2 In order to obtain a more prestigious job later on.

EX3 In order to have a better salary later on.

EX4 Because this will help me make a better choice regarding my career orientation.

EX5 Because without knowing information technology I would not find a high-paying job later on.

EX6 Because I believe that learning information technology is will improve my competence as a worker.

\section{Intrinsic Motivation}

IM1 For the intense feelings I experience when I am communicating my own ideas to others.

IM2 For the pleasure I experience while surpassing myself in my studies.

IM3 For the pleasure that I experience while I am surpassing myself in one of my personal accomplishments.

IM4 Because I experience pleasure and satisfaction while learning new things.

IM5 For the pleasure that I experience in broadening my knowledge about subjects which appeal to me.

IM6 For the pleasure that I experience when I feel completely absorbed by what certain authors have written.

IM7 For the "high" feeling that I experience while reading about various interesting subjects.

\section{$\underline{\text { Amotivation }}$}

AM1 I don't know; I can't understand what I am doing in this class.

AM2 I can't see why I am going to the class and frankly, I couldn't care less.

AM3 I once had good reasons for going to the class; however, now I wonder whether I should.

AM4 Honestly, I don't know; I really feel that I am wasting my time in this class. 